\section{Collaborative Innovating - The Potential of Street Art to Shape Spaces}

GI_Forum 2018, Issue 2

Page: $156-167$

Full Paper

Corresponding Author:

claudia.scharf@uni-due.de

DOI: 10.1553/giscience2018_02_s156

\author{
Claudia Scharf ${ }^{1}$, Inga Gryl ${ }^{1}$, Markus Gamper ${ }^{2}$ and Swantje Weis ${ }^{1}$ \\ IUniversity of Duisburg-Essen, Germany \\ 2University of Cologne, Gemany
}

\begin{abstract}
Research on network theory and innovativeness often addresses innovations. However, network theory lacks theory on innovativeness (the ability to participate in innovation processes), whereas the latter lacks descriptions of network theory. This paper seeks to describe these desiderata, to combine these theoretical research approaches, and to enrich Weis et al.'s (2017) Innovativeness model with network theory in order to describe collaborative innovating. To do this, we use the example of street art, which we view as a form of geomedia that can be created collaboratively as innovations. We will use predominantly the example of the street artist Blek le Rat, whose presumptive embeddedness in social networks we see as an important part of his innovativeness. The final enriched Innovativeness model can contribute to explaining other innovation processes in geography and beyond, to promoting people's abilities to participate in innovation-related communication processes, to changing spatial meanings and to shaping societies.
\end{abstract}

\title{
Keywords:
}

geomedia, street art, innovativeness, innovation networks, participation

\section{Introduction}

In 2017, the video/image instant-messenger application Snapchat and the economically successful artist Jeff Koons announced a collaboration: Snapchat offered a filter that allowed its users to supplement photographs with virtual artistic objects made by Jeff Koons. Among other objects, a typical balloon-dog sculpture was placed in the augmented reality of Central Park (NYC) (Cascone, 2017). The street artist Sebastian Errazuriz then used another platform for augmented reality to reconstruct the dog there, but also to alter it by decorating it with graffiti. Both versions are now available via augmented reality for Central Park visitors.

This example illustrates the complex network between material and digital distribution, political messages and economic purposes as evident in contemporary street art. It also illustrates the conflicts involved with the negotiation of meaning attached to spaces, which 


\section{Scharf et al}

becomes even more complex when the emergence of new media changes current communication practices. During recent years, street art has become a complex system of media: it is geographically located, attaches meanings to spaces, but is also shared, represented and de-localized, e.g. through web2.0. In this paper, we consider street art as geomedia that present innovative approaches towards the shaping of everyday spaces.

When talking about changing and altering spaces, the quality of the change has to be considered - an aspect which has not yet been the subject of research. We argue that this gap could be filled with the help of the Innovativeness model (Weis et al., 2017; see also Gryl, 2013; Jekel et al., 2015), which aims to enable people to participate in innovation processes (Scharf et al., 2017; based on Weis et al., 2017) and can also be used to explain these processes (Weis et al., 2017). Within this approach, collaboration plays an important role, as innovations mark changes in society that clearly go beyond an individual's creative idea and include implementation. Therefore, communication and negotiation are key, and the process can be elaborated on through reference to geomedia. For this, a broad definition of geomedia is used (Schulze, 2017; see also Gryl et al., 2017), including mashups of localised and materialised media, and digital communication platforms: Geomedia are regarded as all media that represent geographical locations and spaces, so that this definition goes beyond visual media only to include sounds and other forms (ibid.).

Street art fits in with the broad term of geomedia by attaching meaning to spaces. Furthermore, this materialised-digitalised form of geomedia is also an innovative praxis, as it develops socio-critical styles, finds inspiration, modifies street-art comments into debates, debates street art as creative acts, and views the negotiating, sharing, copying and modifying of message(s) as acts of implementation. These processes are highly social, thereby making network theories and particularly a combination of innovation and network approaches useful for explaining them in more detail.

Against this background, this paper aims to describe street art as geomedia and a form of participation which emerge and change as a result of collaborative innovative practices. In this approach, we integrate network theories, geomedia theory, and the Innovativeness model in order to explain collaborative aspects in innovation processes. We understand the complex system of street art as highly relevant for shaping urban spaces in particular. Therefore, in this paper we will use (geo)media (with a focus on communication and collaboration) to develop and apply an approach that is useful for explaining processes of spatial innovation generally.

We first describe the characteristics of street art as geomedia that are influenced by current technologies. Thereafter, we introduce the approach of innovativeness, and the need and potential for collaboration within it. Then we outline network theory, based on White (2008), Granovetter (1973) and Burt (2004), and outline the characteristics that foster innovativeness in networks, before applying these theories to the Innovativeness model (Weis et al., 2017). Importantly, the (innovation) network theories used here all describe factors of collaboration and/or participation in innovation processes. Finally, the model is applied to street art as an example of geomedia. 


\section{Beyond the Grey ${ }^{1}$ : Street Art as Geomedia}

In urban areas, street art is an omnipresent artistic communication form. It has its roots in graffiti but extends beyond the strong focus on tags and words towards more visualisationoriented forms of expression (Glaser, 2017); it involves a large variety of techniques, e.g. sprayed images and stencils. At best, street art blends into the physical matter around it or positions itself in relation to it by creating a certain contrast or discontinuity. It always attaches meaning to physical spaces. This meaning can either be new or already exist in social communication. However, meaning is created in interaction with the viewers. Thus, some of the (often-political) messages created by street artists consciously leave room for (re)interpretation by setting out to irritate the viewer or by allowing the artwork to be perceived simply as aesthetic or unaesthetic. The artist-viewer (or author-user) interaction already provides a glimpse into the complex network character of street art, but is only a part of it.

Street art generally involves self-initiated and self-directed participation. Some forms of street art indeed border on the illegal; others are regarded as high art and supported by the municipality, constructing spaces of legality, for instance when the creation of a piece of street art is turned into a public event, or when the artwork becomes an object to shape the public image or is used for touristic purposes (often in areas that are in the process of gentrification). Furthermore, street art may be linked to commercial aims by the secondary usage of artworks on merchandising products. Finally, the art market promotes a small number of street artists (e.g. Banksy, Blek le Rat) and makes their products economically (highly) valuable. This partly strips street art of its 'street cred', and its anarchic roots and reputation. This commercialisation also enriches the network around street art and disseminates new ideas and styles (Derwanz, 2014; Bengtsen, 2013).

Street art normally has a defined geographic address. It has visual or content references to the socially constructed spaces around it and may therefore be linked to the idea of spaces of representation (Lefebvre, 1993), as it stands for certain practices - notably breaking the rules. However, beyond its immediate references, street art also references spaces and represents (parts of) them. Furthermore, it is a combination of visual and symbolic communication forms. Street art attaches meanings to physical matter and, at the same time, visualises meanings that exist in subjective construction and social communication.

In this argumentation, street art is geomedia, a medium representing other media: it refers to a certain position and space, constructing spaces, helping people to appropriate spaces and to alter them for their everyday actions. One may argue as to whether communication about street art without a known geographic reference (e.g. by sharing photos of street art on the web, via blog sites or other social media (Derwanz, 2014)) should itself still be understood as geomedia, as this de-localises and de-contextualises street art. However, many forms of representation consciously create links between street art and spaces. Such representations may start with a linkage to the social construction of 'the street' and urbanity and extend to

\footnotetext{
${ }^{1}$ In the title of this section, we are referencing the documentary 'Das Gegenteil von Grau' (Coers, 2017; 'The opposite of grey', translated by the authors), which is about the appropriation of space in the Ruhr area of Germany.
} 
an augmented-reality guide for visitors using digital maps and geographic coordinates. Apps such as 'Berlin Street Art', for example, work as guides for an enormous outdoor museum, selecting ('curating') street art by making it visible (and invisible).

Street art may function as a dialogue between street artists themselves, and with the public. It inspires others to rethink spaces or to create their own art. By sharing ideas, messages and designs on the web, these are transported even further, sometimes becoming part of a (global) pop culture or of the art market. Street art is thus embedded in networks (Bengtsen, 2013; Derwanz, 2014). Since street art is often shared, by being linked to creative ways of communicating, it can be regarded as innovation because of the combination of deviant appropriation of space(s), transgression, creativity and implementation (McAuliffe, 2012). We bring these aspects of network and innovativeness together, and by focusing on collaboration we utilise street art as an example to improve the Innovativeness model (Weis et al., 2017).

\section{Defining 'Innovativeness'}

Innovativeness is the ability to participate in innovation processes (Scharf et al., 2017; based on Weis, 2016). The term 'innovation' is defined as 'a positively-connoted and intended change' (Gryl, 2013, p. 17, translated by the authors). In the model suggested by Weis et al. (2017) (see Figure 1), innovativeness contains the components 'reflexivity' (questioning current circumstances; reflecting on (one's own) actions), 'creativity' (developing (new) ideas/inventions) and 'implementivity' (convincing others) (see also e.g. Jekel et al., 2015). The phases of innovation processes are 'identifying issues', 'developing solutions' and 'implementing solutions', and all components play a role in any of these phases (Weis et al., 2017). During all these phases, people can innovate 'actively' or 'reactively' (Scharf et al., 2016; see also Hartmann \& Meyer-Wölfing, 2003). The former refers to taking an active role in innovation processes in their entirety or only in a certain phase of these (ibid.); innovating reactively 'refers to reactions to issues and (implementation of) solutions' (Scharf et al., 2017, p. 299), so that not every invention necessarily becomes an innovation, i.e. implemented (Weis et al., 2017). The innovation process does not need to be completed in order to allow participation in it (Scharf et al., 2017). Due to the dynamic nature of such innovation processes, participants can enter, leave and re-enter them at any point (see e.g. Weis, 2016), implying that one does not need to undergo the whole innovation process in order to participate. The approach of education for innovativeness aims to foster people's maturity and capability to participate (see e.g. Weis et al., 2017) ${ }^{2}$. In order to allow participation, we believe that innovation processes must be structured heterarchically and without authority.

\footnotetext{
${ }^{2}$ For more detailed description of the Innovativeness model, see Weis et al. (2017).
} 




Figure 1: The Innovativeness model (based on Weis et al., 2017, pp. 385-86)

We regard participating in street art as participating in innovation processes. Artists and consumers reflect on current circumstances and their own (political) viewpoint(s) as they produce, interpret, share and alter ideas. Practices such as changing street signs are spread via, and openly discussed on, mass media and then adapted in other geographical locations. People can cooperate and participate in innovation processes by using the web to share, comment on or re-design street art digitally. They can even purchase reproductions of street art on merchandising articles to carry around or wear on their bodies, thus delocalising the art from its original context. As a combination of material and digital forms of communication, fluid cultures of street art arise which combine different roles, e.g. territory taggers, political activists, artists, and even managers and curators. These roles speak of a reality in which innovating is not seen as a socially isolated moment of ingenuity (Landry et al, 2001), but rather as involving a broad range of actors in situations of interdependence.

Bornemann (2011) states that creativity is not an individual ability, but rather a social phenomenon, influenced by cultural and interpersonal factors. In the context of innovating, Franke (2005) mentions that it is very unlikely for one person to be able to act in all phases of one innovation process. Rather, he characterises innovating as mostly a 'specialised act of more than one person' (ibid., p. 697; translated by the authors). In addition to the influence 
of other people in general, group dynamics play a role in innovation processes, as Bornemann (2011) describes in the context of creative thinking and acting. In addition to resources such as the environment, budget, time, other group members, (non-)hierarchical structures, appreciation/dislike and interpersonal interaction in general all affect one's thinking and acting (ibid.). If we take into account social psychology, Franke's (2005) argument for the likeliness of the influence of others on innovation processes can be augmented, insofar as social psychology assumes that one is always influenced by others, even when alone (e.g. Aronson et al., 2004).

It follows from this that people are always embedded in different social structures (White, 2008), but not in the same way. Some are more central in a network than others, or have different kinds of relations which are helpful in different contexts. This fact is important, since different networks generate different social capital (Lin, 2002). Innovation needs different kinds of collaboration-networks to allow interaction and the sharing of experiences. Often, people are not aware that they are collaborating in a social network (Bornemann, 2011). Inventors, (street) artists and entrepreneurs influence each other by altering and/or implementing the ideas of others (ibid.), for example if somebody wears a T-shirt with a street-art motif on it, or posts a picture of it on social media. Sawyer (2007, cited in Bornemann, 2011) calls this mutual influence 'invisible collaboration'. The example of street art shows that innovation processes are always socially embedded, with a focus on active and reactive innovating especially.

As the theoretical approach of collaborative innovating is lacking in earlier and present research on innovativeness (e.g. Scharf et al., 2017; Weis et al., 2017), this paper aims to elaborate on the model. The following section describes theoretical approaches to innovation networks. The aim is to draw critical attention to those aspects that can be regarded as fruitful for collaborative innovating.

\section{Innovation Networks}

From the perspective of economic sciences, innovation networks develop when the return on investment is deemed worthwhile by the participants, who are considered to be motivated by opportunism (Lerner \& Tirole 2002; Landry et al., 2001). On this view, such networks are mostly planned and strategic (e.g. Sydow, 1992). From a sociological perspective however, it is not only 'tangible forms of capital (physical, financial, ...)' (Landry et al., 2001, p. 683) that are involved in innovation networks. Abstract forms, too, especially social capital, are involved (ibid.). In this context, the study of Landry et al. (2001), about whether and how social capital determines innovation processes in companies, indicates the strong influence of social capital on the likelihood of participating in innovation processes. Thus, social capital is presented as being more important than return on investment in the generation of innovation networks (ibid.). Social capital, which is captured from 'embedded resources in social networks' (Lin, 2017, p. 3), fosters the probability of achieving several goals (Coleman, 2000) and can occur in different forms (see e.g. Landry et al., 2001): if one has experienced positive interactions with a partner, and/or if partners share the same cooperation culture (norms), and/or if networks are already established, then one is more likely to interact with, 
and trust, this partner again in the future (ibid.). Motivating factors for participating in innovation networks are flow (Lakhani \& Wolf, 2003), mutual support, fun and feelings of identification (Franke \& Shah, 2003). Questions of reputation, expectation of reciprocity and payment play a less important role (ibid.).

One factor in the diffusion of innovations is the strength of the different ties within a network. In an innovation network, everybody can connect to anybody else by referring to a common, even if unknown, acquaintance (Bornemann, 2011). Granovetter (1973) distinguishes between strong and weak interpersonal ties. Strong ties exist to people who are well known and have high emotional intensity, e.g. family members or close friends. The subnetworks (subgraphs) are well connected to each other and have high homophily, i.e. they are homogeneous concerning many characteristics such as hobbies or interests (McPherson et al., 2001). This means that a group usually shares the same social world and therefore the same information (e.g. reads the same newspapers). This can have certain disadvantages, for example restricting the amount of technical advice available within the group (Constant et al,, 1996), or cognitive flexibility (Coser, 1975). At this point, weak ties come into play: Granovetter (1995) shows in a study of successful job applications that weak ties reduce the path length between people and lead to faster diffusion of information processes. New ideas enter the subgraphs and help to create something new. While weak ties help to gain new information, dense networks with many strong ties produce trust and help to disseminate complex information (see e.g. Uzzi, 1997). However, this relatedness may cause people with many ties to get their own way (Bornemann, 2011). In order to avoid this, namely the implementation of ideas that are not based on the strength of the ideas themselves but rather on the number of ties that someone has in a network, it is important to shape the transport of ideas in a transparent manner (Christiakis \& Fowler, 2010, cited in Bornemann, 2011) as well as to foster mutual appreciation of ideas (Bornemann, 2011).

The structure of a network also plays an important role. Burt (1992) discusses the shortage of relationships within networks and the advantages of bridging those gaps. Actors are embedded structurally in the vicinity of nodes from which opportunities for actions and restrictions result (Burt, 1992, 2004). A bridge functions between (two) otherwise separate subgraphs (across a 'structural hole') and has a favourable influence on the bargaining position or innovativeness of individual actors. Therefore, 'Structural hole theory describes how social capital is a function of the [...] opportunities in a network' (Burt et al., 1998, p. 64). Burt (2004) proves his statement about structural holes with a study of managers who generated more ideas for supply-chain management when they were connected with different, heterogeneous, groups than within a densely interconnected network. Strongly related to the argument of weak ties and structural holes is the importance of heterogeneous groups. Both theories show that heterogeneity plays an important role, as it increases creative thinking.

We will illustrate this theoretical concept through the example of the innovative street-art scene $^{3}$. For example, the works of the street artist Banksy, who is considered the creative leader of political street art, are based on the drawings of Blek le Rat. The latter was born in a

\footnotetext{
${ }^{3}$ We are aware that this is only a theoretical approach, without any claim to be a quantifiable network analysis.
} 
very middle-class district of Paris and had an elitist education which brought him into contact with 'classical' art through his parents and friends (strong ties). At university, he met left-wing professors and students (we presume these were weak ties), from whom he learned that art is not just for elites, and that the urban world is a political space. Through his networks and the influence of the university, he brought his art to the streets and became a political activist. Working as a volunteer in playgrounds and in contact with poorer children, he met Gérard Dumas. Together, they used to spray walls during le Rat's time at the university, where he changed courses from art to architecture. His innovative work, in turn, influenced other artists. This short example shows the connection between social networks, heterogeneity and the combination of strong and weak ties, which taken together produce new ideas. Without le Rat's presumptive embeddedness in different networks and his position as an artist who was broke, this kind of work would not exist - and maybe the work of other famous street artists like Banksy would not exist either.

\section{Discussion: Collaborative Innovativeness in Street Art Networks}

The aspects of collaborative innovating presented in the previous section can be transferred to Weis et al.'s (2017) Innovativeness model. Innovating can be cooperative if someone discovers a problem, then someone else develops an idea to solve it, and yet another fosters the implementation of this idea. However, first, one is always influenced by and dependent on others, so that linking an idea solely to one person is never a possibility. Secondly, the existence of active and reactive innovating shows that there are always feedback loops, which can be established only collaboratively. Transferring this aspect to street art implies that one piece of art created by one person is never solely the product of only this particular person, but an accumulation of thoughts, reflections and ideas shared across social ties, as the example of Blek le Rat shows.

Street art, which may aim to criticise current issues and therefore may inspire viewers to think critically, cannot, in this sense, be explained by the return-on-investment theory, but rather by the social-capital theory. Of course, it would be possible to focus on fame and profit, but such a focus is not in accordance with the Innovativeness model, as it aims at emancipation.

We believe (contrary to Gemünden and Högl (2005, cited in Bornemann, 2011)) that members of an innovation network who are participating in an innovation process do not necessarily need to be aiming for the same goal. If anything, innovation processes are processes of negotiation. For example, one person can participate in the same innovation process for atom-bomb development by not aiming at developing an atom bomb at all and yet be considered innovative more than ever. This is also the case if, for example, political regulations are implemented and street artists reactively innovate against them (see Figure 2). 




Figure 2: Joshua Woodrow: 'Trump grabbing liberty by the pussy', poster on utility box, Farragut Square Park at Connecticut Avenue and I Street, NW, Washington (Elvert Bames Protest Photography, 2017).

Using Granovetter's (1973) theory of the 'strength of weak ties', one's innovativeness is stronger if many weak ties are present, since the heterogeneity of these ties provides different views on the world. 'The fewer indirect contacts one has the more encapsulated he will be in terms of knowledge of the world beyond his own friendship circle' (Granovetter, 1973, p. 1371). In our example, Blek le Rat presumably had weak ties to left-thinking students, and to poorer children in the playground, who influenced his thinking on the arts, and made him more political as an artist. Conversely, one can be dismayed by a piece of (political) street art and influenced to create a project directed against its particular content.

Structural holes (Burt, 1992) not only foster innovativeness as a whole because of heterogeneous, interpersonal exchange, but also facilitate collaborative innovating. In the example of street art, this particular genre has a big impact on the art scene in general, as the popularity of artists like Basquiat or Haring indicate (McAuliffe, 2012; Derwanz, 2014). Blek le Rat occupied a bridging position between different social classes as well as between contemporary and classical art. This (mutual) influence among artists themselves as well as among (casual) viewers in different innovation processes sometimes occurs without their being aware of it - as Bansky was influenced by le Rat without even noticing (Coan, 2008).

Digital media especially provide certain advantages for collaboration (Bennett et al., 2009; Derwanz, 2014) and can create different kinds of global networks in which one has many weak ties. This form of media can be in a bridging position between different styles (structural holes). For instance, social media networks provide the option to debate in fluent communities and to initiate and organise grassroots movements (Elwood \& Mitchell, 2013). Therefore, 'public art can be seen to contribute to the production of an innovative creative milieu within which creativity can be nurtured and flourish' (McAuliffe, 2012, p. 194; see also Landry, 2000). 


\section{Conclusion}

Street art provides an example for other innovation processes that may profit from a network approach embedded in the Innovativeness model. The network approach may be essential, as participation in street art seems to happen in localised and delocalised networks of actors (this needs to be validated empirically). The Innovativeness model can contribute to understanding networks and innovation processes in spatial decision-making processes like street art, since the model supports participation in innovation processes, paying attention to the dynamics of (innovative) action in social groups.

The approach of collaborative innovating is suitable for interpreting and analysing complex systems of street art and the variety of actions conducted by multiple actors. The focus of this paper is on aspects of network theories that are likely to be found within the street-art context and that can enrich the Innovativeness model with theoretical aspects of collaborative innovating: weak ties, structural holes and heterogeneity. This means, in our example, that Blek le Rat's kind of innovative art and political statements in social street and transnational spaces (e.g. on the web), as well as art which is influenced by him, might never have happened without his presumptive embeddedness in different social networks.

Even though the Innovativeness model can be seen as an instrument for describing collaborative innovation processes, it needs further theoretical underpinning - it lacks the theoretical background for breaking down innovation processes (e.g. Reinhard, 2017), and stronger network-analysis is missing. As our short example shows, deeper analysis can advance innovation research as well as research into innovativeness. Against this background, innovation research should focus more on the embeddedness of street artists and their communication structures.

As the example of Blek le Rat shows, innovation processes seem to be connected to networks. While studies on creative ideas in companies (Burt, 2004) and the networks of creative companies (Uzzi, 1997) have been able to show the effect of networks on innovation and the connections between the two, research in the field of street art, which is embedded in the field of media and in space, is still completely lacking. Contact with different people can lead to exposure to different views and thereby help produce innovation. However, nobody has analysed yet how social networks are involved in the innovating process, or how street artists influence each other or other people, and vice versa, within a network approach. To our mind, it would be fruitful to combine the approach of innovativeness with social network analysis. The concepts of tie strength, structural holes and heterogeneity in particular may help to give a more nuanced view of innovation processes in street art, and the methods of social-network analysis may help to provide a relational view on such processes (Carrington et al., 2005). 


\section{Scharf et al}

\section{References}

Aronson, E., Wilson, T., \& Akert, R. (2004). Sozialpsychologie. München: Pearson.

Becker, S. (2014). Zehn Jahre ALG II. https://www.deutschlandfunknova.de/beitrag/zehn-jahre-hartziv-von-entt $\% \mathrm{C} 3 \%$ A4uschung-und-wut.

Bengtsen, P. (2013). Site Specificity and Street Art. In J. Elkins, K. McGuire (Eds.), Theorizing Visual Studies. Writing Through the Discipline. New York: Routledge, 250-253.

Bennett, W.L., Wells, C., \& Rank, A. (2009). Young citizens and civic learning. Citizenship Studies 13(2), 105-120.

Bornemann, S. (2011). Kooperation und Kollaboration. Wiesbaden: Springer.

Burt, R. S. (1992). Structural Holes. Cambridge: Harvard University Press.

Burt, R. S., Jannotta, J. E., \& Mahoney, J. T. (1998). Personality correlates of structural holes. Social Networks, 20, 63-84.

Burt, R. S. (2004). Structural Holes and Good Ideas. American Journal of Sociology, 110(2), 349-399.

Carrington, P. J., Scott, J., \& Wasserman, S. (Eds.). (2005). Models and methods in social network analysis (Vol. 28). Cambridge: University press.

Cascone, Sarah (2017): Snapchat Unites With Jeff Koons for a Globe-Spanning Augmented Reality Sculpture Project. https://news.artnet.com/art-world/snapchat-reveals-massive-jeff-koons-sculpturesaugmented-reality-partnership-1103774.

Christakis, N., \& Fowler, J. (2010). Connected. Die Macht sozialer Netzwerke und warum Glück ansteckend ist. Frankfurt/Main: Fischer.

Coan, L. (2008). Breaking the Banksy: The first interview with the world's most elusive artists.

http://www.dailymail.co.uk/home/moslive/article-1024130/Breaking-Banksy-The-interview-

worlds-elusive-artist.html.

Coers, M. (2017). Das Gegenteil von Grau. http://gegenteilgrau.de/.

Coleman, J. S. (2000). Social capital in the creation of human capital. In P. Dasgupta, \& I. Serageldin (Eds.), Social Capital. Washington: World Bank, 13-39.

Constant, D., Sproull, L., Kiesler, S. (1996). The kindness of strangers. Organization Science, 7(2), 119135.

Coser, R. (1975). The complexity of roles as seedbed of individual autonomy. In ibid. (Ed.), The idea of social structure. NY: Harcourt.

Derwanz, H. (2014). Street Art-Karrieren. Bielefeld: transcript.

Elvert Barnes Protest Photography (2017). Image of: Joshua Woodrow: Trump grabbing liberty by the pussy, poster on utility box at Farragut Square Park at Connecticut Avenue and I Street, NW, Washington. https://www.flickr.com/photos/95413346@N00/32640826100.

Elwood, S., \& Mitchell, K. (2013). Another politics is possible. Cartographica, 48(4), 275-292.

Franke, N. (2005). Open Source \& Co. In S. Albers, O. Gassmann (Eds.), Handbuch Technologie- und Innovationsmanagement. Wiesbaden: Gabler, 695-712.

Franke, N., \& Shah, S. (2003). How Communities Support Innovative Activities. Research Policy, 32(1), 157-178.

Gemünden, H. G., \& Högl, M. (2005). Teamarbeit in innovativen Projekten: Eine kritische Bestandsaufnahme der empirischen Forschung. In: Högl, M., \& Gemünden, H.G. (Eds.), Management von Teams. Theoretische Konzepte und empirische Befunde, 3rd. Ed., Wiesbaden: Deutscher Universitäts-Verlag, 1-32.

Glaser, K. (2017). Street art und neue Medien. Bielefeld: transcript.

Granovetter, M.S. (1973). The Strength of Weak Ties. American Journal of Sociology, 78(6), 1360-1380.

Granovetter, M.S. (1995). Getting a job. A study of contacts and careers. Chicago: University of Chicago Press.

Gryl, I. (2013). Alles neu? GW-Unterricht 131, 16-27.

Gryl, I., Scharf, C., Weis, S, \& Schulze, U. (2017). Geomedia and Spaces of the In-between. GI_Forum 2, 49-59. 


\section{Scharf et al}

Hartmann, T., \& Meyer-Wölfing, E. (2003). Nutzung von Innovationspotentialen in außerbetrieblichen Handlungs- und Lernfeldern. QUEM-Report 83, 3-127.

Jekel, T., Ferber, N., \& Stuppacher, K. (2015). Innovation vs. innovativeness. GI-Forum, 373-381.

Lefebvre, H. (1993). The production of space. Oxford: Blackwell.

Lakhani, K., \& Wolf, R. G. (2003): Why Hackers Do What They Do, MIT Working Paper, 4425, 1-27.

Landry, C. (2000). The creative city. London: Earthscan.

Landry, R., Amara, N., Lamari, M. (2001). Does social capital determine innovation? Technological Forecasting \& Social Change, 69(7), 681-701.

Lerner, J., \& Tirole, J. (2002). Some Simple Economics of Open Source. Journal of Industrial Economics, 50(2), 197-234.

Lin, N. (2002). Social Capital. Cambridge: University Press.

Lin, N. (2017). Building a network theory of social capital. In ibid. (Ed.), Social capital, Cambridge: University Press, 3-28.

McAuliffe, C. (2012). Graffiti or street art? Journal of Urban Affairs, 34(2), 189-206.

McPherson, M., Smith-Lovin, L., \& Cook, J.M. (2001). Birds of a feather. Annual review of sociology, $27(1), 415-444$.

Reinhard, M. (2017). Philosophie des Scheiterns. Weilerswist: Velbrück.

Sawyer, K. (2007). Group Genius: the creative power of collaboration. New York: Basic-Books.

Scharf, C., Schmitz, S., \& Gryl, I. (2016). Innovativeness as fresh ground. GI-Forum, 1, 250-261.

Scharf, C., Weis, S., \& Gryl, I. (2017). Innovative Pupils. The European Conference on Education: Official Conference Proceedings, 295-313.

Schulze, U. (2017). Geoinformationsausbildung in der Hochschule: Kompetenzen, curriculare Anforderungen und empirische Befunde. Kumulative dissertation at the Johann-Wolfgang Goethe-University of Frankfurt (Main). FFM.

Sydow, J. (1992). Strategische Netzwerke. Wiesbaden: Gabler.

Uzzi, B. (1997). Social structure and competition in interfirm networks. Administrative science quarterly, 42(1), 35-67.

Weis, S. (2016). Schüler als Entdecker, Erfinder, Erneuerer? Unpublished examination paper at the University of Duisburg-Essen, Essen.

Weis, S., Scharf, C., Greifzu, L., \& Gryl, I. (2017). Stimulating by simulating. International Conference on Education: Conference Proceedings, 386/1-386/11.

White, H. C. (2008). Identity and Control. Princeton, Oxford: University Press. 